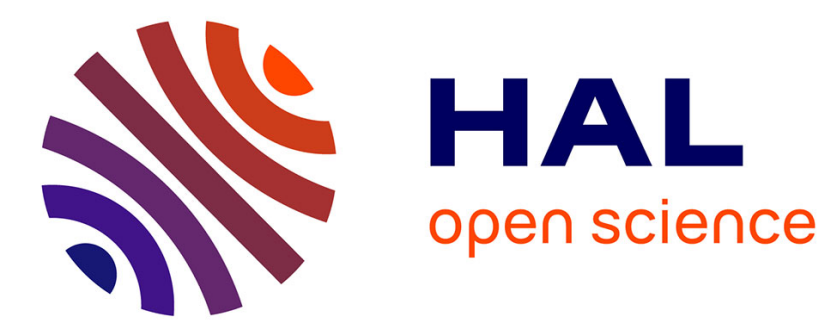

\title{
Local Approach: Numerical Simulations of Creep and Creep-Fatigue Crack Initiation and Crack Growth in 316L SPH Austenitic Stainless Steel
}

D. Poquillon, M.-T. Cabrillat, André Pineau

\section{- To cite this version:}

D. Poquillon, M.-T. Cabrillat, André Pineau. Local Approach: Numerical Simulations of Creep and Creep-Fatigue Crack Initiation and Crack Growth in 316L SPH Austenitic Stainless Steel. Journal de Physique IV Proceedings, 1996, 06 (C6), pp.C6-421-C6-430. 10.1051/jp4:1996642 . jpa-00254475

HAL Id: jpa-00254475

https://hal.science/jpa-00254475

Submitted on 1 Jan 1996

HAL is a multi-disciplinary open access archive for the deposit and dissemination of scientific research documents, whether they are published or not. The documents may come from teaching and research institutions in France or abroad, or from public or private research centers.
L'archive ouverte pluridisciplinaire HAL, est destinée au dépôt et à la diffusion de documents scientifiques de niveau recherche, publiés ou non, émanant des établissements d'enseignement et de recherche français ou étrangers, des laboratoires publics ou privés. 


\title{
Local Approach: Numerical Simulations of Creep and Creep-Fatigue Crack Initiation and Crack Growth in 316L SPH Austenitic Stainless Steel
}

\author{
D. Poquillon, M.-T. Cabrillat and A. Pineau* \\ CEA Cadarache, DER/SERA/LDCS, Bâtiment 204, 13108 Saint-Paul-lez-Durance, France \\ * URA 866 du CNRS, Centre des Matériaux Pierre-Marie Fourt, BP. 87, 91003 Evry, France
}

\begin{abstract}
This study deals with the evaluation of local approach to assess the mechanical integrity of cracked components submitted to cyclic and steady load at elevated temperature. In this approach, a fracture criterion based on calculated intergranular damage ahead of the crack tip is introduce to simulate both crack initiation and crack propagation in $316 \mathrm{~L}$ type austenitic stainless steel. This numerical method, based on finite element computations is firstly described. Then numerical results are compared with sets of experimental data for two specimen geometries during load controlled tests. A damage criterion in good agreement with previous studies leads to promising load-displacement response, crack initiation and crack growth curves.
\end{abstract}

\section{INTRODUCTION.}

Usually, for the integrity assessment of defective components, well established rules are used. In those rules based on global approach to fracture, the cracked body is described with a single load geometry parameter, such as $\mathrm{K}, J$ or $\mathrm{C}^{*}$. But the global approach to fracture is far from physically based damage evolution and not well adapted to time dependent creep, complex loadings, interaction (creep-fatigue, corrosion...).

A more fundamental way to deal with these problems is based on the local approach to fracture, which relies on several scientific and technical fields (damage mechanics, physically based damage evolution models, numerical methods...).

In this paper, we simulate creep and creep-fatigue crack initiation and crack propagation, with a finite element code. An incremental discrete propagation and an adaptative remeshing technique are chosen.

The damage model used was identified at the 'Ecole des Mines de Paris' (EMP). This identification relies on metallographical measurements of intergranular damage $D$ on notched creep specimens [1].

In a first part of this work, we focus on creep behaviour. Two or three simulations with different values of the fracture criterion Dc are computed for each of the 20 samples of two specimen geometry types. Then we choose the value of $\mathrm{Dc}$ that fits best the experimental data. On that basis, creep-fatigue test simulations are performed.

\section{MATERIAL BEHAVIOUR AND DAMAGE OF AUSTENITIC STEEL AT HIGH TEMPERATURE.}

\subsection{Experimental data.}

Experimental studies on creep and creep-fatigue reveal a large scatter in test results. So a comparison with several tests on different geometry specimens is necessary.

Furthermore, the mechanical properties of $316 \mathrm{~L}$ steel vary from one heat to another. So, having a large amount of experimental results from a single heat of $316 \mathrm{~L}$ steel was the first condition before starting this numerical study. At the 'Centre des Materiaux' (CDM) of the 'Ecole des Mines de Paris' (EMP), $316 \mathrm{~L}$ 
SPH steel (SQ heat) has been largely investigated through many creep and creep-fatigue tests carried out essentially at $600^{\circ} \mathrm{C}$.

It is the reason why we have chosen in [1] 20 experimental tests performed on two specimen geometry types. In all of them, the observations showed that the fracture mode was predominantly intergranular. Furthermore, the mechanical properties of the steel were well established. The specimen geometries are shown in figure 1. The CT specimens have no side grooving and have a small thickness

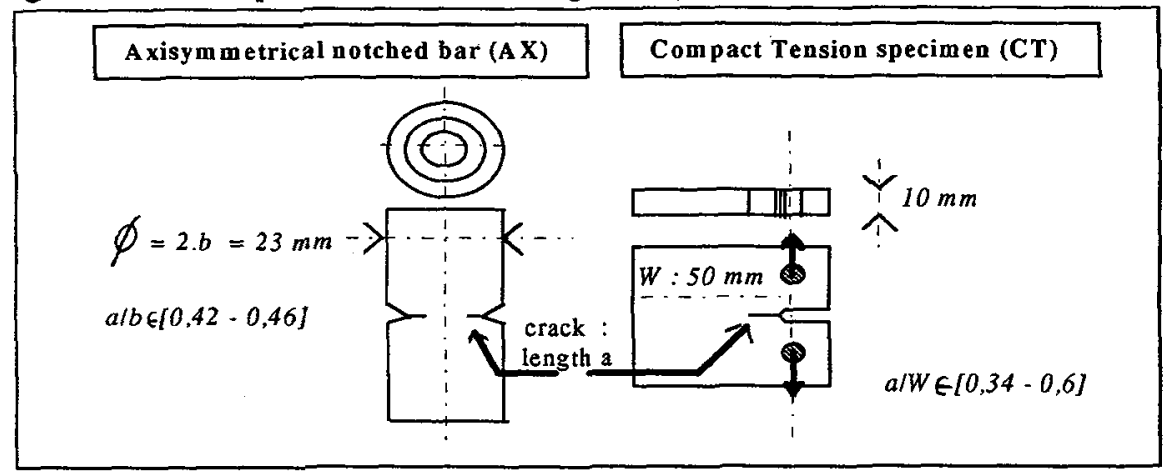

Figure 1 : The two specimen geometries : Compact Tension specimen (CT) and axisymmetrical notched bar (AX)

\subsection{Material behaviour constitutive model.}

As explained above, the only material used in these simulations was the SQ heat of $316 \mathrm{~L}$ austenitic stainless steel whose chemical composition and mechanical properties were taken from [1]. All the test on which are based the simulations were performed at $600^{\circ} \mathrm{C}$.

One of the key element of an inelastic failure analysis are the material constitutive equations which describe the deformation under load.

\subsubsection{For creep simulations.}

We use the material constitutive model taken from [1]. Two different mechanical models are used : elastoplasticity (elastoplastic isotropic behaviour with the true stress-strain curve in uniaxial tension) during the initial loading followed by creep under steady load.

The creep behaviour is a combination of primary and secondary creep. Both are isotropic. The primary creep is assumed to follow strain hardening rule.

\subsubsection{For creep-fatigue simulations.}

We use the Chaboche viscoplastic model [2] in order to be able to take into account the strong cyclic hardening of the material and its viscoplastic behaviour during hold time.

This model is used in a two centre kinematic and isotropic form. The 24 coefficients of the model were taken from [3] and [4]. Some minor changes were done to fit better the SQ heat properties.

As this model has a single inelastic strain, the creep strain is assumed to be the strain occurring during hold time whereas the plastic strain is assumed to occur elsewhere. So we introduce a new scalar field: the effective creep strain, which is the summation of the effective Mises inelastic strain occurring during hold time.

\subsection{Damage model.}

Damage in $316 \mathrm{~L}$ steel tested at $600^{\circ} \mathrm{C}$ either on notched specimens or on cracked specimens and with dwell period, is mainly intergranular [1]. At the crack tip, cavities nucleate, grow, and coalesce mainly on grain-boundaries as shown schematically in figure 2. 


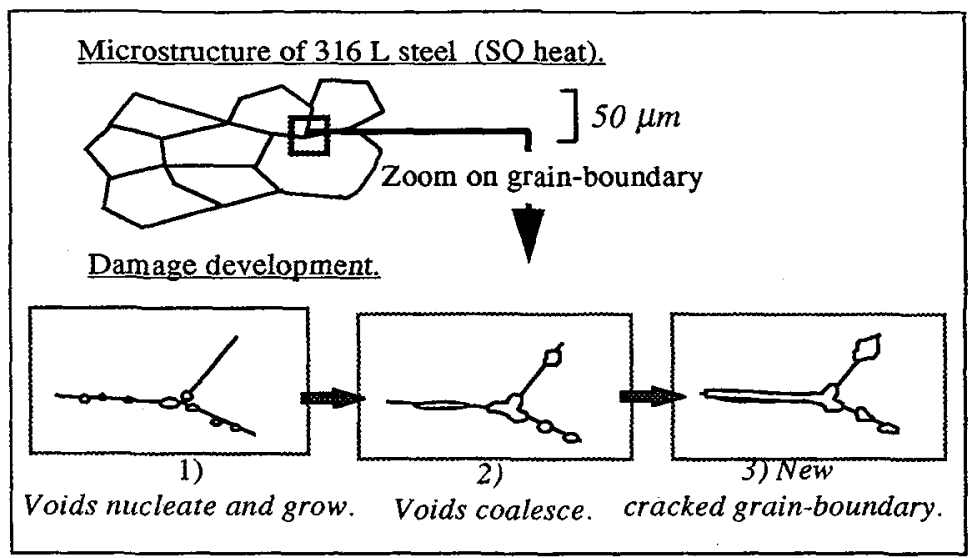

Figure 2: Damage in $316 \mathrm{~L}$ steel at $600^{\circ} \mathrm{C}$, during dwell period.

One of the key element of this damage is the localisation of cavities. Actually this kind of damage is wholly different of ductile damage where cavities grow in the entire volume of the grains and where fracture is transgranular.

A number of metallurgical studies $[1,5-14]$ of stainless austenitic steel damage at high temperature generally agree with the following characteristics. The intergranular damage is :

- sensitive to inelastic strain,

- sensitive to the effective Mises stress,

- preferentially located on grain boundaries facets perpendicular to the principal stress,

- and occurs only in tensile hold time.

The real difficulty of the problem comes from the gap between the two points of view : the micro-scale (voids $\sim>\mathrm{m}$ ) and the engineer-scale $(\sim>\mathrm{mm}$ or $\mathrm{cm}$ ). So, the damage criterion and fracture criterion used in modelling the phenomenon depend on authors. In [5-14] we can find different models using the maximum principal stress, the effective Mises stress, the effective Mises strain or a more complex damage criterion calculated from strain and stress tensors.

2.3.1 Creep intergranular damage model used for the simulations.

A series of studies based on quantitative observations of grain boundary damage ([1], [15-17]) leads to a damage scalar variable D calculated and summed during the life of the material, with the following expression :

$$
\mathrm{dD}=\mathrm{A}\left\langle\sigma_{1}\right\rangle^{2} \frac{1}{\sqrt{\bar{\varepsilon}_{\text {creep }}}} \mathrm{d} \bar{\varepsilon} \text { creep }
$$

Where $\langle x\rangle=x$ if $x>0,\langle x\rangle=0$ if $x<0, A$ is a constant depending on steel and temperature, $\sigma_{1}$ is the maximum principal stress and $\bar{\varepsilon}$ creep the effective Mises creep strain.

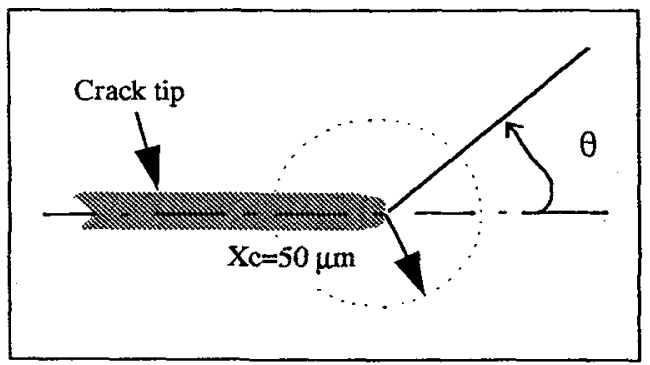

Figure $3:$ Damage fracture criterion at the crack tip and $\theta$ definition. 
We have chosen to work with this model not only because it takes into account both the creep strain and the maximum principal stress, but also because it was well qualified from numerous tests on notched specimens.

As far as $D$ represents intergranular damage, the fracture criterion is reached when $D$ reached Dc (critical damage) at a distance $\mathrm{Xc}$ from the crack tip (cf. figure 3 ). $\mathrm{Xc}$ is a definite material dimension : it is the average grain size.

When $\mathrm{D}=\mathrm{Dc}$ somewhere on a circle centred on the crack with a radius $\mathrm{Xc}$, then the whole grain-boundary is supposed to be broken and the crack grows. The discrete crack increment is Xc in length. The first step is called 'initiation'.

\section{FINITE ELEMENT SIMULATION OF CREEP AND CREEP-FATIGUE CRACK GROWTH.}

The finite element code used is Castem 2000 [18]. It can cope with parametrical mesh, inelastic behaviour (plasticity, viscoplasticity...), large displacements option and fundamental operations on tensors (damage field computations). In order to limit computation time and costs, we manage to find a specific algorithm for these simulations.

\subsection{Meshes}

On the one hand, for each of the two specimen geometries, meshes have to be adapted to a 1-2 mm crack propagation. On the other hand, the purpose of local approach is to have accurate mechanical fields at the crack tip for a good damage evaluation. This second point requires highly refined meshes.

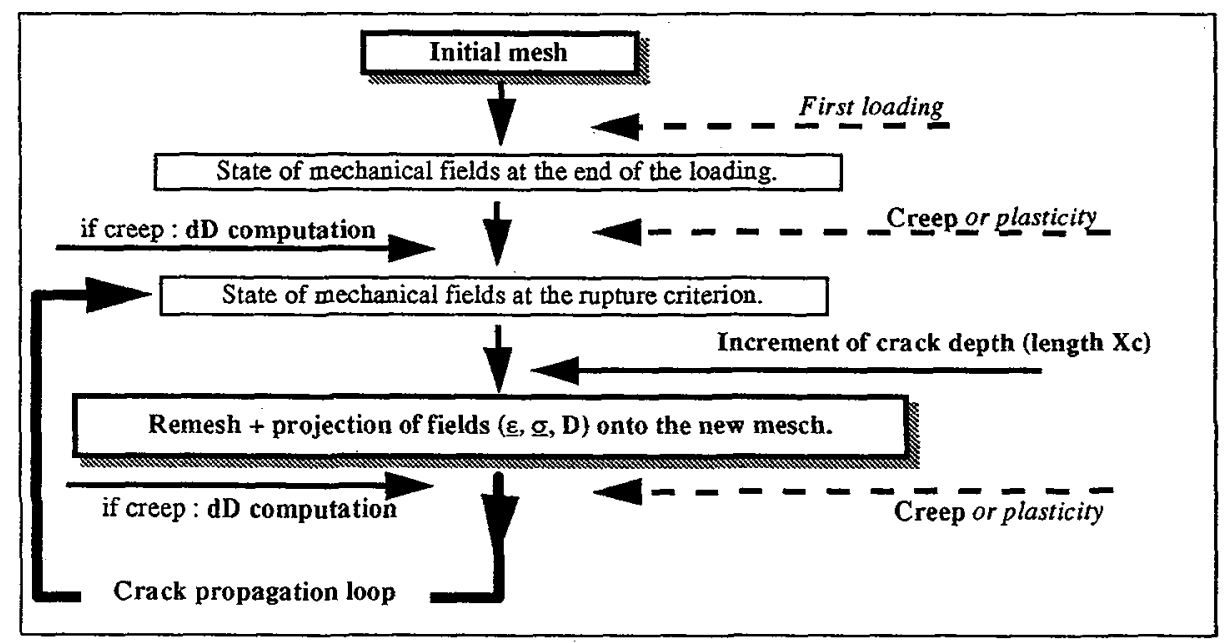

Figure 4 : Algorithm for crack propagation.

The two specimen geometries of our simulations are axisymmetrically notched bar (AX) and Compact Tension (CT) samples as shown in figure 1. More detailed descriptions and dimensions are available in [1].

Because of the symmetry of geometry and load, a 2D axisymmetrical calculation is adopted for the AX specimens. The small thickness of the CT specimens allows us to perform a 2D plane stress computation. The load-line displacement curves during the initial loading confirm that plane stress is well adapted Although the fracture criterion is taken all around the crack tip (cf. figure 3), in this study, the crack is supposed to advance in its plane. So only a quarter ( res. a half) of the AX ( res. CT) sample has to be meshed. 
A mesh geometry adapted to the mechanical fields is chosen, with an adaptative remeshing at each discrete increment of crack growth (cf. figures $4 \& 5$ and $\S 3.2$ ).

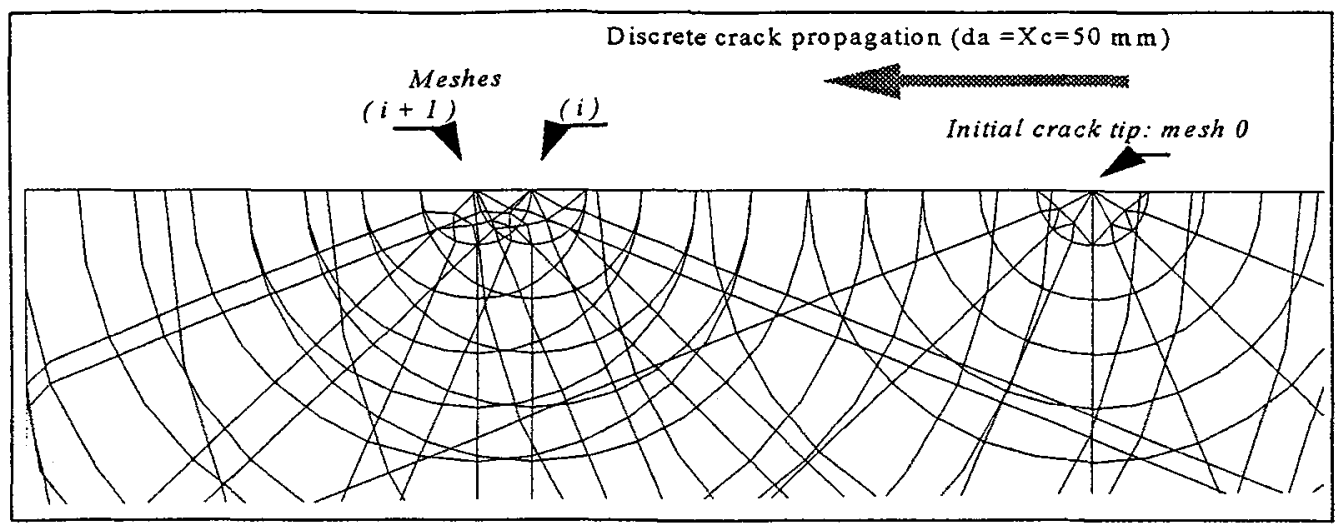

Figure 5 : Adaptative remeshing, at the crack tip, during crack propagation.

Two types of elements are used, usual 8-node isoparametric elements and 6-node isoparametric elements. A half CT specimen is modelled with about 1000 nodes. A quarter of AX specimen is modelled with about 300 elements, essentially 8-node isoparametric elements. The small strain and large displacement options are used in the FE code. The iterative computations described in the next paragraph are performed, for example on a SUN Spark Station 10, in 2 to 8 hours. This duration depends on the applied stress and on the fracture criterion Dc.

To validate our mesh for a local approach to fracture, on each simulation, after the initial loading (elastoplastic analysis) and before any stress redistribution, we check the following points. If, the mesh size at the crack tip is divided by two (res. doubled) then, at $\mathrm{XC}=50 \mu \mathrm{m}$ from the crack tip, the variations of the maximum principal stress and of the effective Mises stress have to be lower than $1 \%$ to consider that the adopted mesh size is appropriate. As this moment is before any stress redistribution, the stress singularity is supposed to be maximal. The effects of the projection of the former mechanical fields onto the new mesh are evaluated for the first rupture only. The variations at Xc from the new crack tip, on the crack axis, are less than $1 \%$. For the following ruptures, this point is not checked again.

\subsection{Scheme of the simulations.}

All the tests on which are based the simulations are load controlled situations. Initially, the crack is supposed to be infinitely sharp because the specimens are fatigue-precracked at $20^{\circ} \mathrm{C}$. The Crack Tip Opening Displacement (CTOD) results from the initial loading.

\subsubsection{Creep tests.}

The algorithm used for the creep simulation is now detailed. The first step is the initial loading, during which the material behaviour is elastoplastic. No damage occurs during this initial step.

Then, the incremental creep and damage are computed until the fracture criterion Dc is reached at Xc from the crack tip. A new mesh, with a crack length increase by $\mathrm{Xc}$, is created. The mechanical and damage fields are projected onto this new mesh. Creep and damage are accumulated until Dc is reached at the new crack tip and so on...

Figure 4 gives a scheme of the method.

\subsubsection{Creep-fatigue tests.}

In case of creep-fatigue loading, the behaviour is described by the viscoplastic Chaboche model.

The creep strain is suppose to occur only during hold time, as the damage. So at each step of the computation, we check if there is fatigue or creep. 
Then, the incremental damage is computed according to Eq.1, with the creep strain specified in $\S 2.2 .2$, and the crack propagation loop follows the same scheme than for creep propagation (cf. figure 4).

This deserves a word of comment : the creep-fatigue crack propagation in these simulations is determined only by creep effect. Our purpose is to evaluate the creep damage during creep-fatigue test.

Additive and/or multiplicative combinations with, for example Paris crack growth rules, should be performed after for the cases where creep is not the dominant effect. Further studies will investigate this aspect which was out of the scope of the present study.

\subsection{Results of creep simulations.}

Two or three simulations with different value for the fracture criterion Dc in a range of $2 \%$ to $3.5 \%$ are computed for each of the 20 specimens. For the CT specimens (cf. [1]), the load is in a range of 2.77 to $9.2 \mathrm{kN}$ and $\mathrm{a} / \mathrm{W}$ in a range of 0.34 to 0.6 . For the AX specimens the load is in a range of 36.5 to $52.6 \mathrm{kN}$ and $\mathrm{a} / \mathrm{b}$ (cf. figure 1 ) in a range of 0.42 to 0.46 .

The best fitted crack growth estimation of the whole set of the experimental data is obtained for $\mathrm{Dc}=2.5 \%$. This value is in good agreement with former studies $[1,19]$. The two next paragraphs detail these creep results

\subsubsection{Load-line displacement and crack growth curves.}

For each sample, there are two experimental curves : the load-line displacement curve $\delta(t)$ and the crack propagation curve $a(t)$. Globally, the experimental and computed curves are in good agreement. However, the simulations tend to slightly overestimate the opening displacement $\delta(t)$. Figure 6 is an example of results for an AX specimen.

Crack initiation is more sensitive to this value of $\mathrm{Dc}$ than crack propagation : the initiation time depends exponentially on Dc, but not the crack propagation rate. The more Dc increases, the longer the EMP damage accumulates ahead of the crack tip accordingly reducing the next propagation step. So the Dc

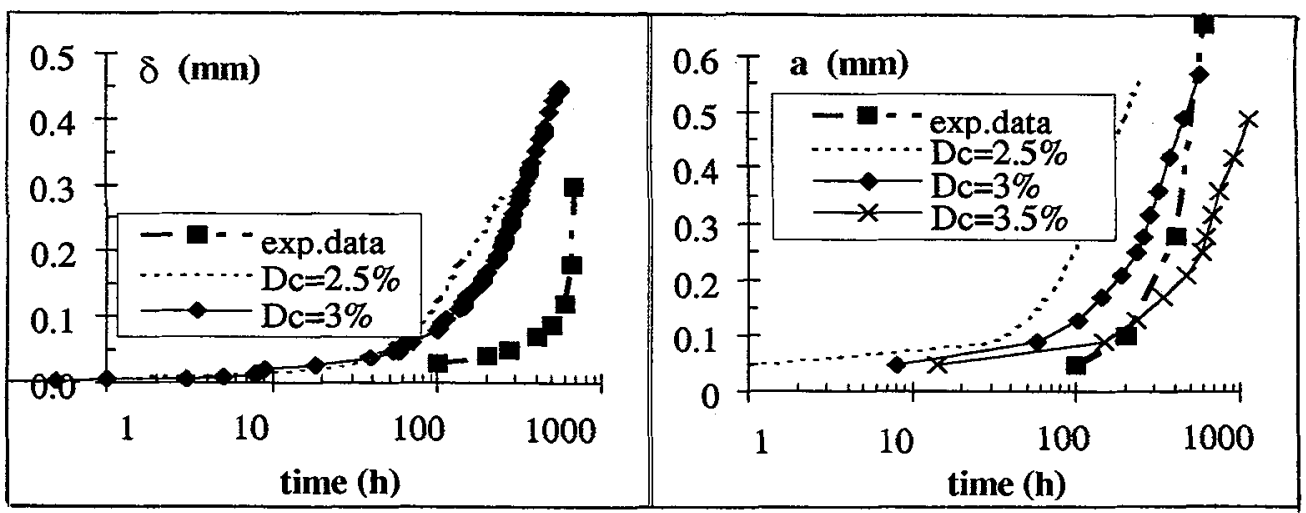

Figure $6: \mathrm{AX} 12\{\mathrm{a} / \mathrm{b}=0.436 ; \mathrm{P}=46.88 \mathrm{kN}\}$ Displacement $\delta$ and crack propagation a.

value of $2.5 \%$ was chosen in order to obtain a good agreement with experimental data for both initiation and propagation.

Nevertheless, the method tends to give too short initiation times for specimens with reference stress of the order of 200-230 MPa but fits better their propagation curves. The lower the load is, the less conservative the simulation is. The best fitted results are obtained with reference stress of the order of 160-200 MPa. Under $150 \mathrm{MPa}$, creep laws are not as accurate and under-estimate the creep strain. This implies an under-estimation of damage. 


\subsubsection{Local analysis at the crack tip.}

In these computations, the qualitative evolution of mechanical variables at the crack tip is excellent, successive remeshings and projections apparently do not lead to too much distortion.

According to microscopic observations, crack tip blunting is important during the initial loading (before initiation) but, during propagation creep crack remains relatively sharp. Figure 7 is an example of what is observed during a simulation.

On this figure, in order to show this directly with the mesh of the AX13 specimen, we have projected

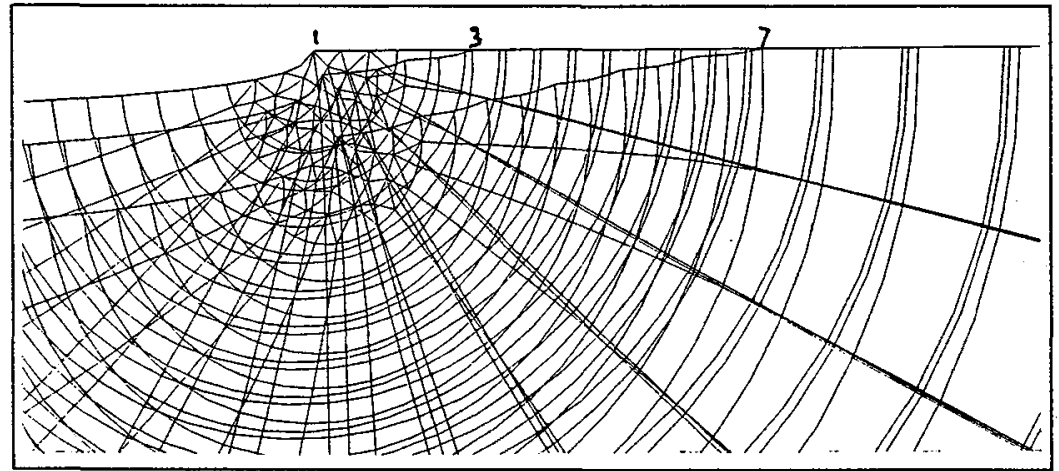

Figure 7: $\mathrm{AX} 13\{\mathrm{a} / \mathrm{b}=0.448 ; \mathrm{P}=41.68 \mathrm{kN}\} \mathrm{Dc}=2.5 \%$, Successive bluntings in simulations.

three different states of the displacement field onto the initial mesh : at the initiation stage (here Dc $=2.5 \%$ ), at the third fracture step, at the seventh fracture step.

The damage localisation observed in the two specimen geometry types is as different as stress triaxiality.

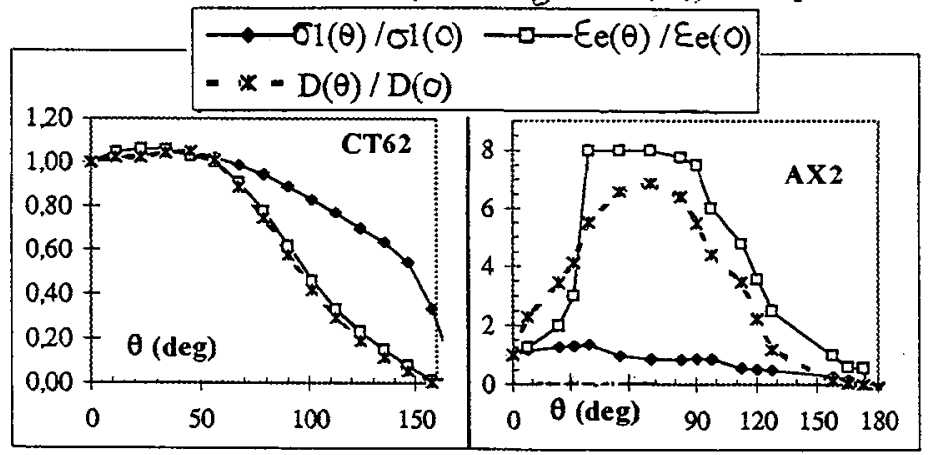

Figure 8 : Comparative angular analysis at $0.25 \mathrm{~mm}$ from the crack tip, after $25 \mathrm{~h}$ of creep. $\sigma_{1}$ is the main stress, $\varepsilon_{a}$ the effective Mises creep strain and D the EMP damage ( $\theta$ is defined on figure 3 ).

Damage localisation differs (cf. figure 8 ) between the two geometry types and, surprisingly (the stress $\Sigma$ has a power 2 in Eq. 1), seems essentially to depend on creep strain localisation. This specific point requires further investigations about the respective importance of the maximum principal stress and the equivalent creep strain. A solution is to obtain dissymmetrical mechanical fields on each side of the crack plane.

Shear loading (Mode II fracture) or mixed loading (mode I and mode II) are therefore interesting to consider and a future paper will give more details about the results obtained under these conditions.

The fracture criterion is roughly reached along the crack axis for the CT specimens, but at about $+/-65$ degrees on both sides of the crack for the AX specimens (cf. figure 8). As we assume in the computations that the crack $(\theta=0)$ is a symmetry axis, we make the crack propagate in its plane even if for the AX 
specimen the maximum damage is reached at $\theta=65$ and $\theta=-65$. So, no crack branching is considered. Furthermore, to take it into account would be relevant only with a complete mesh of the AX specimen.

A last point to conclude with creep simulations : even if the damage localisation of the AX simulations and of the CT simulations are different, the global curves have the same aspect: the CT simulations are as accurate as the $\mathrm{AX}$ simulations.

So the hypothesis of plane stress conditions for the CT specimens seems to be reasonable while there was no approximation in the $\mathrm{AX}$ specimen computations.

\subsection{Creep-fatigue simulations.}

As for the creep simulations, the load-line displacement curves and the crack growth curves are the main points of comparison between simulations and experimental data. Four different load controlled tests are simulated. All are performed on CT specimens.

The ratio $\mathrm{R}$ between the minimum load and the maximum load is 0.1 and during simulations no crack closure is observed. The initial crack ratio of all the specimens is near 0.6 .

The main difference between these tests taken from [1] is the duration of the dwell time : from 1.4 to 48 hours.

In § 3.2.2 we explained that we focus only on creep damage and the simulation results detailed in the next paragraph show, unsurprisingly, that the longer is the hold time, the better are the results.

\subsubsection{Global curves.}

The comparison between the experimental crack growth curves and the simulated ones is good for the 48 hour hold time specimen (cf. figure 9). There, creep seems to be the dominant element.

On the contrary, the 1.4 hour hold time test is predominantly fatigue dominated. So taking into account only creep crack growth effect gives us a too small crack growth rate.

The results for the other specimens are logically between the two former.

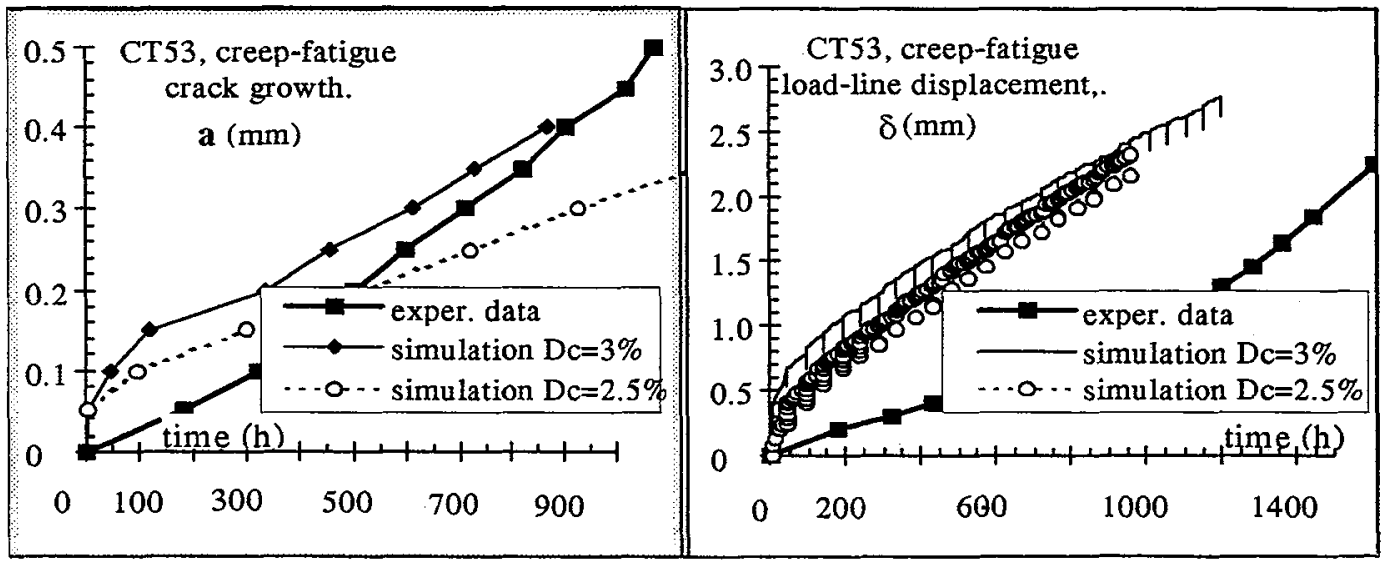

Figure 9: CT53 $\{\mathrm{a} / \mathrm{W}=0.6025, \mathrm{~F}=3,38 \mathrm{kN}, 48 \mathrm{~h}$ hold time $\}$

It should be pointed out that all the samples experienced hold time lower than the initiation time, Ti, defined, e.g. in [1], on pure creep tests as the duration necessary to initiate crack growth over a distance of $50 \mu \mathrm{m}$.

Further work is clearly needed. In particular, the application of the local approach requires that the complex interactions between plasticity and viscoplasticity, such as the effect of cyclic hardening on creep behaviour, are taken into account. 


\subsubsection{Analysis at the crack tip.}

The mechanical and damage fields at the crack tip have the same characteristics than those obtained during CT specimen creep test simulations.

The blunting effect is just less important but no crack closure effect is observed during the simulations.

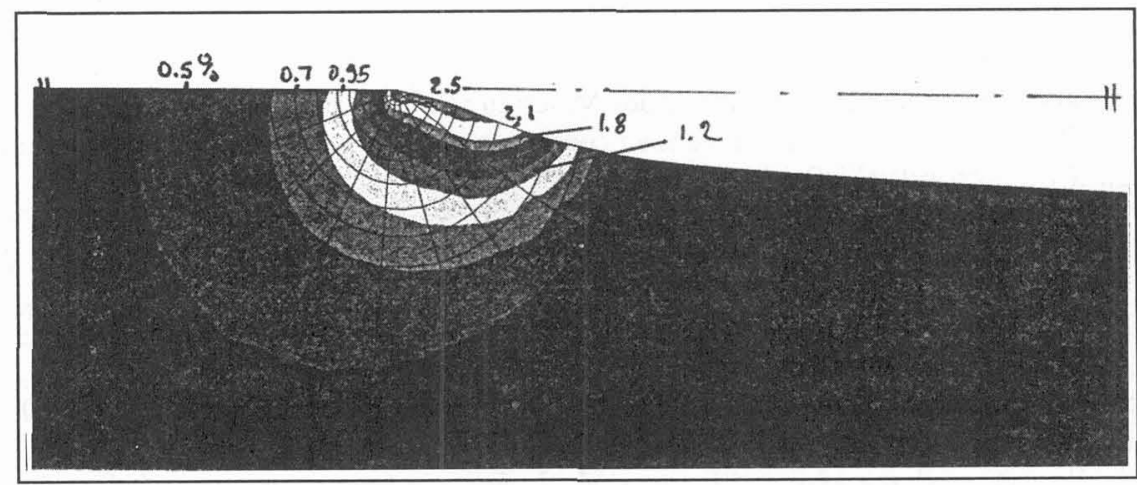

Figure 10 : CT53, Dc=2\%, crack tip damage field at rupture 11 (cycle $\left.\mathrm{n}^{\circ} 16\right)$.

The history of the sample clearly appears in the damage field as shown in. figure 10.

\section{CONCLUSION.}

The intergranular creep damage model used in the present study, combined with the chosen adaptative FE approach (remeshing) can cope with situations where the crack advances in its plane.

A large set of experimental tests for two specimen types were simulated.

In this local approach of creep and creep-fatigue crack growth a damage criterion $\mathrm{Dc}=2.5 \%$ is in good agreement with experimental load-line displacement and crack growth curves.

Crack initiation is more sensitive to the value of $\mathrm{Dc}$ than crack propagation : the initiation time depends exponentially on Dc, but not the crack propagation. The more Dc increases, the longer the calculated intergranular damage accumulates ahead of the crack tip accordingly reducing the next propagation step. So the Dc value was chosen in order to get a good agreement with experimental data for both crack initiation and crack propagation.

We would like also to point out the importance of the mechanical behaviour model. A calculation in which the creep behaviour would be reduced to secondary creep would not be realistic : for all the creep simulations the accumulation of damage takes place essentially during the first tens hours when primary creep is dominant. So, it would be incorrect to neglect it.

Besides, the Chaboche viscoplastic model used for creep-fatigue simulation takes into account the strong cyclic hardening of the material.

Performing creep damage local approach requires a good material behaviour basis. But it is difficult to have accurate models able to take into account cyclic hardening and creep in a wild range of applied stress $(100-400 \mathrm{MPa})$.

In conclusion, it is worth emphasizing the originality of this study : local approach to fracture has already been applied to ductile fracture, but the adaptative remeshing technique and the intergranular creep damage model used in the present study are a new numerical method, based on the local approach to fracture, to simulate both crack initiation and crack growth.

The next steps of the study, will concern other creep-fatigue test conditions with the same damage law and other 316L SPH steel heats. Additive and/or multiplicative combinations with, for example Paris 
crack growth rules, will also be performed for the cases where creep is not the dominant effect. Problems where crack advances out of its plane will be also considered and especially creep mode II loadings.

\section{References :}

[1] Piques R., Mécanique et mécanismes de l'amorçage et de la propagation des fissures en viscoplasticité dans un acier inoxydable austénitique.(thesis, sciences et génie des matériaux, Ecole Nationale Supérieure des Mines de Paris, 1989).

[2] Lemaitre J.and ChabocheJ-L., Mécanique des Matériaux Solides, (Dunod, Paris, 1988), p. 310-325.

[3] Engel J-J., Rousselier G., 'Comportement en contrainte uniaxiale sous chargement cyclique de l'acier austenitique..',( Rapport Edf HT/PV D 599 MAT/T 43, 1983).

[4] Rive D., Escaravage C., Riou B. and Cabrillat M-T., 'Creep fatigue analysis of LMFBR'S structures. Identification of Chaboche's models for the stainless steel 316 SPH', SMIRT 11, Tokyo, 1991 (paper L06/1).

[5] Hales R., 'The role of cavity growth mechanisms in determining creep-rupture under multiaxial stresses', Fatigue Fract. Engng Mater. Struct, 17, 5, (1994) p. 579-591.

[6] Bestwick R.D., and Buckthorpe D.E., 'Strain based creep-fatigue design rules', Fatigue Fract. Engng Mater. Struct 17, 7, (1994) p. 849-859.

[7] Simon S., Rodriguez Ibabe J.M. and Fuentes M 'Low cycle fatigue and creep-fatigue behaviour of a 316L stainless steel', Zeitschrift Für Metallkunde, 84, 10, (1993) p.708-715.

[8] Ainsworth R.A. and Budden P.J., Design and assessment of components subjected to creep, Journal of Strain Analysis, 29, 3 (1994) ,p. 201-208.

[9] Bensussan P., Piques R.and Pineau A. 'A critical assessment of global mechanical approaches to creep crack initiation and creep crack growth in 316L steel', Non Linear Fracture Mechanics, vol I. Time Dependent Fracture,(ASTM STP 995, 1989) p.27-54.

[10] Skelton R. P. 'Damage factors during high temperature fatigue crack growth',ESIS 15, Behaviour of defects at high temperatures, in R.A. Ainsworth and R.P. Skelton eds., (Mechanical Engineering Publications, London, 1993) p. 191-217.

[11] Riedel H., Fracture at High Temperature, (Springer-Verlag; Berlin, 1987).

[12] Maas E. and Pineau, A. 'Creep crack growth behaviour of a $316 \mathrm{~L}$ steel', Engineering Fracture Mechanics 22, 2, (1985), p. 307-325.

[13] Saxena A. 'Creep crack growth in high temperature ductile materials', Engineering Fracture Mechanics, 40, 4/5, (1991) p. 721-736.

[14] Bensussan P., Maas E., Pelloux R and Pineau A. 'Creep crack initiation and propagation : fracture mechanics and local approach', Jour. of Pres. Vess. Technology, 110, (1988), p. 42-50

[15] Levaillant C., Approche métallographique de l'endommagement d'aciers inoxydables austénitiques sollicités en fatigue plastique ou en fluage.(thesis; UTC Compiègne, 1984).

[16] Diboine A., Influence de la triaxialité des contraintes sur la cavitation intergranulaire induite par fluage d'un acier austénitique.(D.E.A rapport, C.D.M, Ecole Nationale Superieure des Mines de Paris,1982)

[17] Yoshida M., Endommagement intergranulaire de fluage dans un acier inoxydable $17 \mathrm{Cr}-12 \mathrm{Ni}$ : étude quantitative - rôle de la multiaxialité des contraintes.( thesis, sciences et génie des matériaux, Ecole Nationale Supérieure des Mines de Paris, 1985).

[18] Hoffmann A and Combescure A,'Castem, a system of finite element computer programs', paper 40, Conference on Structural Analysis, Design and Construction in Nuclear Power Plant, Porto Alegre, Brazil,1978.

[19] Laiarinandrasana L., Amorçage et propagation de fissure à haute température dans un acier inoxydable austénitique. (thesis, sciences et génie des matériaux., Ecole Nationale Supérieure des Mines de Paris, 1994). 